\title{
Inappropriate Dosing Of Direct Oral Anticoagulants In Patients With Atrial Fibrillation
}

\author{
Katy Lavoie ${ }^{1,}$, Marie-Hélène Turgeon ${ }^{2}$, Caroline Brais ${ }^{3}$, Josiane Larochelle ${ }^{4}$, Lucie Blais ${ }^{5,6}$, Paul Farand ${ }^{1,7}$, Geneviève \\ templier ${ }^{1,7}$, Sylvie Perreault ${ }^{5}$, Marie-France Beauchesne ${ }^{1,5,7,8}$. \\ ${ }^{1}$ Faculté de médecine et des sciences de la santé, Université de Sherbrooke, Sherbrooke, Québec, Canada. ${ }^{2}$ Centre hospitalier \\ universitaire de Montréal, Montréal, Canada. ${ }^{3}$ Hôpital du Haut-Richelieu, Saint-Jean-sur-Richelieu, Québec, Canada. \\ Institut universitaire de gériatrie de Sherbrooke, Sherbrooke, Québec, Canada. ${ }^{5}$ Faculté de pharmacie, Université de Montréal, \\ Montréal, Québec, Canada. ${ }^{6}$ Centre de recherche, Hôpital du Sacré-Coeur de Montréal, Montréal, Québec, Canada. ${ }^{7}$ Centre \\ hospitalier universitaire de Sherbrooke, Sherbrooke, Québec, Canada. ${ }^{8}$ Centre de recherche, Centre hospitalier universitaire de \\ Sherbrooke, Sherbrooke, Québec, Canada.
}

\begin{abstract}
Atrial fibrillation (AF) is a common cardiovascular disease for which newer oral anticoagulants are available. The main objective of this study was to evaluate the appropriateness in prescriptions of direct oral anticoagulant (DOACs), more specifically apixaban, dabigatran and rivaroxaban. This was a single-centre, retrospective study conducted in the province of Quebec, Canada. Adult subjects hospitalized between October 2011 and October 2014, with a diagnosis of AF, and a DOAC prescription were included. Data were retrieved from the electronic medical records and prescriptions were evaluated according to appropriateness criteria. A total of 500 subjects were included ( 235 subjects on dabigatran, 222 on rivaroxaban and 43 on apixaban). Overall, $70.4 \%$ (95\% confidence interval [Cl] 66.4-74.1) of DOAC prescriptions were considered appropriate. About $24 \%$ of subjects received an inappropriate dose of apixaban, dabigatran or rivaroxaban. A reduced dose was prescribed in $56.8 \%$ of subjects with no clear indication, and $43.2 \%$ received a dose that was not reduced while indicated. DOACs were frequently prescribed at a dose that was considered inappropriate. There is a need to strengthen dosing recommendations of DOACs in clinical practice.
\end{abstract}

\section{Introduction}

Atrial fibrillation $(\mathrm{AF})$ is the most common type of cardiac arrhythmia. AF affects between $1 \%$ and $2 \%$ of the population and its prevalence increases with age ${ }^{[1,2]} . \mathrm{AF}$ is associated with a three to five-fold increased risk of ischemic stroke, and anticoagulants are effective in preventing thromboembolic events ${ }^{[3,4]}$. Vitamin $\mathrm{k}$ antagonists (warfarin) have mainly been used in $\mathrm{AF}$ management, but direct oral anticoagulants (DOACs) such as dabigatran, rivaroxaban and apixaban are increasingly used. DOACs have a rapid onset of action, few food drug interactions, and blood monitoring is required less frequently when compared with warfarin. However, DOACs are contraindicated in patients with severe renal failure (creatinine clearance $[\mathrm{CrCl}]<25-30 \mathrm{~mL} / \mathrm{min}$ ), and not all have antidotes to reverse their effect ${ }^{[5,6]}$. Selecting the appropriate dosing of DOACs is important

Key words

Atrial fibrillation, direct oral anticoagulants, apixaban, dabigatran, rivaroxaban

Corresponding Author:

Faculty of Medicine and Health Sciences,

Université de Sherbrooke, Sherbrooke,

Quebec,

Canada marie-france.beauchesne@umontreal.ca. to prevent thromboembolic events and reduce the risk of bleeding. Warfarin has been used for several years and its efficacy and longterm safety are well known ${ }^{[5]}$. However, only a few real-world studies on DOACs have been published ${ }^{[7-14]}$. Short-term studies have confirmed the efficacy and safety of DOACs in $\mathrm{AF}^{[15-17]}$, but it is essential to evaluate their appropriateness in use. Thus, the main objective of this study was to evaluate overall appropriateness in prescriptions of DOACs in adults with AF.

Material and methods

Study design and study population

A retrospective cohort study was conducted in a single centre (Centre hospitalier universitaire de Sherbrooke, Quebec, Canada). The study population included subjects hospitalized between October 2011 and October 2014, with a diagnosis of AF documented on the discharge summary. Subjects were identified using ICD-10 codes (International Statistical Classification of Diseases and Related Health Problems - 10th revision) for the diagnosis of AF (I48X, I48.XN-001 and I48.XN-002). Medical records were reviewed to determine eligibility (inclusion and exclusion criteria are listed in Table 1). Only the first hospitalization following October 1th 2011, was selected. 
Data Collection:

Electronic medical records were reviewed, more specifically the discharge summary, laboratory data (values that were closest to DOAC prescription), and discharge prescriptions. Data collected for each subject were sociodemographic characteristics (age, gender, weight, height and body mass index), serum creatinine (to estimate renal function using the Cockcroft-Gault equation), liver enzymes, comorbidities, length of stay, healthcare unit of admission, concomitant medications that are contraindicated with DOACs (ketoconazole, itraconazole, voriconazole, posoconazole and ritonavir) or known to increase bleeding risks (antiplatelets and nonsteroidal anti-inflammatory drugs (NSAIDS). Valvular AF was determined when the diagnosis was specified on the discharge summary or in the presence of mitral or tricuspid valve replacement or repair.

Appropriateness in Prescriptions:

The appropriateness criteria were developed and reviewed by the

\begin{tabular}{|c|c|}
\hline Inclusion and & lusion criteria \\
\hline Inclusion criteria & Exclusion criteria \\
\hline $\begin{array}{l}\text { - At least } 18 \text { years of age at the time of } \\
\text { hospitalization }\end{array}$ & $\begin{array}{l}\text {-AF associated with: congenital heart disease, } \\
\text { uncontrolled hyperthyroidism, illicit drug or } \\
\text { drug intoxication }\end{array}$ \\
\hline $\begin{array}{l}\text { - Diagnosis of AF documented on the } \\
\text { discharge summary }\end{array}$ & $\begin{array}{l}\text {-Another indication for } \\
\text { anticoagulation such as deep vein thrombosis, } \\
\text { pulmonary embolism, orthopedic surgery or } \\
\text { hypercoagulable state }\end{array}$ \\
\hline $\begin{array}{l}\text {-DOAC prescribed during } \\
\text { hospitalization and at discharge }\end{array}$ & - AF with a duration of less than 48 hours \\
\hline $\begin{array}{l}\text {-Availability of a discharge prescription } \\
\text { and the list of usual medications }\end{array}$ & - Peri-operative AF \\
\hline
\end{tabular}

anticoagulotherapy committee of our institution. The criteria were mainly based on DOACs product monographs along with the 2012 update of Canadian Society of Cardiology (CSC) guidelines [1822]. The appropriateness criteria used are presented in Table 2. A total of 8 appropriateness criteria were evaluated for each subject included in the study.

Statistical Analyses

Baseline characteristics were described estimating means, medians, standard deviations, ranges and proportions with $95 \%$ confidence intervals (CI). The proportion (with $95 \% \mathrm{CI}$ ) of prescriptions that were in accordance with each of the 8 appropriateness criteria was initially calculated. Then, the proportion (with 95\% CI) of prescriptions that were in accordance with all appropriateness criteria for a given DOAC was estimated. Statistical analyses were performed using the IBM SPSS Statistics software.

Ethical Considerations

This project was approved by the ethics committee of our institution. Data were kept confidential using a denominalized database.

Results

A total of 1051 subjects were initially screened for their eligibility, and 551 were excluded (Figure 1). Most of them had an exclusion criterion $(n=417)$ and 134 were previously selected (more than one hospitalization). The main reasons for exclusion were the lack of a discharge prescription (80.3\%), DOAC not prescribed at discharge (17.0\%) and anticoagulation for an orthopedic surgery (7.4\%). Thus, 500 subjects were included, 235 on dabigatran, 222 on rivaroxaban and 43 on apixaban. More patients were on dabigatran and rivarox-
Criteria

\section{Type of AF}

DOACs are prescribed in patients with non-valvular AF (i.e. mitral or tricuspid valve replacement or repair) [18].

\section{Mitral stenosis}

In the case of mitral stenosis, DOACS are prescribed in patients with mild to moderate mitral stenosis only (not moderate to severe) [18]

\section{CHADS2 score}

When DOACs are prescribed, the CHADS2 score is $\geq 1$.

If the CHADS2 score $=0$, the CHA2DS2-VASc score must be $\geq 2$ or there has been a cardioversion [18].

\section{Heart valves}

In the case of heart valves, DOACs are used in patients with a bioprosthetic valve (and not a mechanical valve) [19].

5. Concomitant medication

DOACs are prescribed in patients that do not use ketoconazole, itraconazole, voriconazole, posaconazole or ritonavir [5, 20-22].

\section{Renal function}

Dabigatran and rivaroxaban are prescribed when the estimated $\mathrm{CrCl}$ is $\geq 30 \mathrm{~mL} / \mathrm{min}[5,21$, 22].

Apixaban is prescribed when $\mathrm{CrCl}$ is $\geq 25 \mathrm{~mL} / \mathrm{min}$ [20].

7. Liver enzyme levels

DOACs are prescribed if blood levels of AST and ALT are $\leq$ twice the upper limit of normal [5].

\section{8. a. Dose of dabigatran}

Dabigatran is prescribed at a reduced dose of $110 \mathrm{mg}$ twice daily if one of the following factors is present:

- Weight $<50 \mathrm{~kg}$

- Age $\geq 80$ years old

- Haemorrhagic risk factors: HAS-BLED score $\geq 3$ and/or $\mathrm{CrCl}$ is between 30 and $49 \mathrm{~mL} / \mathrm{min}$ [5. 21].

\section{8. b. Dose of rivaroxaban}

Rivaroxaban is prescribed at a reduced dose of $15 \mathrm{mg}$ once daily if $\mathrm{CrCl}$ is between 30 and 49 $\mathrm{mL} / \min [5,22]$.

8. c. Dose of apixaban

Apixaban is prescribed at a reduced dose of $2.5 \mathrm{mg}$ twice daily when 2 of the 3 following criteria are present:

Serum creatinine $>133 \mu \mathrm{mol} / \mathrm{L}$

- Age $\geq 80$ years old

-Weight $\leq 60 \mathrm{~kg}[5,20]$

Legend: $\mathrm{CrCl}$, creatinine clearance; CHADS2: Congestive Heart Failure, Hypertension, Age $\geq 75$ years, Diabetes, Stroke; CHA2DS2-VASc: Congestive Heart Failure, Hypertension, Age $\geq 75$ years old, Diabetes, Stroke history, Vascular disease, Age between 65 and 74 years, Sex Category; HASBLED: Hypertension, Abnormal renal and/or liver function, Stroke, Bleeding, Labile INR, Elderly, Drugs.

aban because they were introduced earlier (October 2011, and March 2013, respectively), than apixaban (January 2014) on the therapeutic formulary. Excluded and included subjects had similar baseline characteristics (Supplementary Table 1).

Table 3 presents sociodemographic characteristics, hospitalization data, laboratory values, comorbidities, and concomitant drugs. Data on compliance related to each appropriateness criteria are found in Table 4. Subjects were 74 years old on average, and about half were males (52.4\%). Most subjects (71\%) had a body mass index (BMI) greater than $25.0 \mathrm{~kg} / \mathrm{m} 2$. Subjects were mainly hospitalized at the cardiology unit (41.0\%), followed by internal medicine (21.4\%), family medicine (17.0\%), neurology (8.6\%) and respiratory medicine units (3.4\%). Moreover, $63.4 \%$ of subjects were previously anticoagulated.

Overall, 70.4\% (95\%CI 66.4-74.4) of subjects were prescribed a DOAC in accordance with all criteria. A high proportion of subjects (94.6\%) had a thromboembolic score (CHADS2 score) equal to or greater than 1. In patients who had a CHADS2 score of $0(n=27), 13$ had a CHA2DS2-VA2Sc score of at least to 2 and/or a cardioversion, and 6 had a surgical ablation. About 3\% of patients had valvular AF and $1.0 \%$, moderate to severe mitral stenosis. No patients had a me- 


\begin{tabular}{|c|c|c|}
\hline Baseline & aracteristics of incl & ded patients $(n=500)$ \\
\hline Characteristics & & $\mathbf{n}(\%)$ * \\
\hline $\begin{array}{l}\text { Age (years), mean } \pm \mathrm{SD} \\
\text { Male gender } \\
\mathrm{BMI}(\mathrm{kg} / \mathrm{m} 2)^{\circ}\end{array}$ & $\begin{array}{l}<18.5 \\
18.5-24.9 \\
25.0-29.9 \\
\geq 30.0\end{array}$ & $\begin{array}{l}74.3 \pm 11.5 \\
262(52.4) \\
12(2.4) \\
132(26.6) \\
164(33.0) \\
189(38.0)\end{array}$ \\
\hline $\begin{array}{l}\text { Hospitalization data } \\
\text { Length of stay, median; range (days) } \\
\text { Health Care units }\end{array}$ & $\begin{array}{l}\text { Cardiology } \\
\text { Internal medicine } \\
\text { Family medicine } \\
\text { Neurology } \\
\text { Surgery } \\
\text { Respirology } \text { Others }^{1}\end{array}$ & $\begin{array}{l}5 ; 1-70 \\
205(41.0) \\
107(21.4) \\
85(17.0) \\
43(8.6) \\
22(4.4) \\
17(3.4) \\
21(4.2)\end{array}$ \\
\hline $\begin{array}{l}\text { Laboratory data } \\
\mathrm{CrCl}(\mathrm{CG}), \text { median; range }(\mathrm{mL} / \mathrm{min})^{\circ} \\
\mathrm{CrCl}<30 \mathrm{~mL} / \mathrm{min} \\
\text { Level of liver enzymes }^{\circ}\end{array}$ & $\begin{array}{l}\text { AST, median ; } \\
\text { range }(\mathrm{U} / \mathrm{L}) \\
\text { ALT, median ; } \\
\text { range }(\mathrm{U} / \mathrm{L})\end{array}$ & $\begin{array}{l}63.9 ; 20.4-120.0 \\
11(2.2) \\
21 ; 8-155 \\
17 ; 5-529\end{array}$ \\
\hline $\begin{array}{l}\text { Clinical data } \\
\text { Atrial flutter } \\
\text { Valvular AF } \\
\text { Mitral stenosis }\end{array}$ & $\begin{array}{l}\text { Mild to moderate } \\
\text { Moderate to } \\
\text { severe }\end{array}$ & $\begin{array}{l}79(15.8) \\
13(2.6) \\
25(5.0) \\
5(1.0)\end{array}$ \\
\hline $\begin{array}{l}\text { Biological heart valve } \\
\text { Congestive heart failure } \\
\text { Hypertension } \\
\text { Diabetes } \\
\text { Stroke } \\
\text { Atherosclerotic heart disease } \\
\text { Atherosclerotic vascular disease } \\
\text { Cirrhosis } \\
\text { CHADS2 } \geq 1 \\
\text { CHADS2-VA2Sc } \geq 2\end{array}$ & & $\begin{array}{l}13(2.6) \\
183(36.6) \\
397(79.4) \\
157(31.4) \\
139(27.8) \\
212(42.4) \\
84(16.8) \\
5(5.2) \\
473(94.6) \\
455(91.0)\end{array}$ \\
\hline $\begin{array}{l}\text { Drugs } \\
\text { Number of drugs at discharge, } \\
\text { median ; range } \\
\text { Antiplatelets } \\
\text { NSAIDs } \\
\text { DOACs user's type }\end{array}$ & $\begin{array}{l}\text { Prevalent } \\
\text { Incident } \\
\text { Switch }\end{array}$ & $\begin{array}{l}10 ; 2-8 \\
82(16.4) \\
30(6.0) \\
317(63.4) \\
148(29.6) \\
35(7.0)\end{array}$ \\
\hline
\end{tabular}

scribed $20 \mathrm{mg}$. For patients on apixaban, $30.2 \%$ received a dose of 2.5 $\mathrm{mg}$ without having two characteristics justifying this reduced dose.

Discussion

DOACs were frequently prescribed at a reduced dose in adults

1051 subjects identified from medical archives

\section{7 subjects excluded}

REASONS FOR EXCLUSION *

$\rightarrow$ No discharge prescription $(n=335)$

$\rightarrow$ No DOAC prescribed at discharge $(n=71)$

$\rightarrow$ Anticoagulation for orthopedic surgery $(n=31)$

$\rightarrow$ Anticoagulation for a venous thromboembolism ( $n=13$ )

$\rightarrow$ Peri-operative $\mathrm{AF}(\mathrm{n}=6)$

$\rightarrow$ AF associated with a congenital heart disease ( $n=5)$

$\rightarrow \mathrm{AF}$ associated with an uncontrolled hyperthyroidism $(\mathrm{n}=2)$

$\rightarrow$ Anticoagulation for a hypercoagulable state $(n=2)$

* A patient may have more than one reason for exclusion.

\begin{tabular}{|c|}
\hline $\begin{array}{c}\text { Subjects excluded because they } \\
\text { had already been included } \\
(\mathrm{n}=134)\end{array}$ \\
\hline
\end{tabular}

$\mathbf{5 0 0}$ subjects included

235 subjects on dabigatran

222 subjects on rivaroxaban

43 subjects on apixaban

Figure 1:

Flow chart for subjects selection

with AF. Up to a third of patients were prescribed a dose of dabigatran that was considered inappropriate. Proportions of inappropriate dosing (without specification for under or overdosing) of dabigatran (14.4\%) and rivaroxaban (35.4\%) has been reported ${ }^{[7][13]}$. A Danish study reported that only $55.5 \%$ of subjects were prescribed $150 \mathrm{mg}$ of dabigatran while indicated (a lower dose was used) ${ }^{[14]}$. Larock et al. reported that the dosage of dabigatran was reduced in $10.1 \%$ of subjects with no clear indication, while $4.3 \%$ of subjects had a regular dose when a reduction was indicated ${ }^{[12]}$. Finally, up to a third of subjects were prescribed a dose of apixaban that was considered inappropriate, but some clinicians might reduce the dose in the presence of only one justification factor.

We found a lower proportion of subjects with valvular disease (2.6\%) than the ones reported by Larock et al. $(7.2 \%)^{[12]}$ and Carley et al. $(10.9 \%)^{[8]}$, but it was similar to the one found by Armbruster et al. $(2.8 \%)^{[7]}$. DOACs were rarely prescribed in subjects with moderate to severe mitral stenosis (1.0\%), which was also described by Tellor et al. ( $0.8 \%$ of patients with moderate to severe mitral stenosis received rivaroxaban) ${ }^{[13]}$, and Armbruster et al. (0.2\% of patients with moderate to severe mitral stenosis received a dose of dabigatran) ${ }^{[7]}$.

Most of our patients had a CHADS2 score greater than or equal to one. At the time of the study, we considered the prescription of DOACs in patients who were 65 years and over with a CHADS2 score of 0 inappropriate (this represents 8 patients), 
Supplements:

\section{Supplementary Table 1:}

\begin{tabular}{|c|c|c|c|}
\hline Characteristics & & $\begin{array}{l}\text { Patients } \\
\text { included } \\
(n=500) \\
n(\%) *\end{array}$ & $\begin{array}{l}\text { Patients excluded } \\
(n=417) \\
n(\%) *\end{array}$ \\
\hline $\begin{array}{l}\text { Age (years), mean } \pm \text { SD } \\
\text { Male gender }\end{array}$ & & $\begin{array}{l}74.3 \pm 11.5 \\
262(52.4)\end{array}$ & $\begin{array}{l}70.5 \pm 13.5 \\
258(61.9)\end{array}$ \\
\hline \multicolumn{4}{|l|}{ Hospitalization data } \\
\hline $\begin{array}{l}\text { Length of stay, median; } \\
\text { range (days) }\end{array}$ & Cardiology & $\begin{array}{l}5 ; 1-70 \\
205(41.0)\end{array}$ & $\begin{array}{l}4 ; 1-85 \\
205(49.2)\end{array}$ \\
\hline \multirow[t]{7}{*}{ Care units } & Internal medicine & $107(21.4)$ & $35(8.4)$ \\
\hline & Family medicine & $85(17.0)$ & $16(3.8)$ \\
\hline & Neurology & $43(8.6)$ & $31(7.4)$ \\
\hline & Surgery & $22(4.4)$ & $37(8.9)$ \\
\hline & Respirology & $17(3.4)$ & $5(3.6)$ \\
\hline & Orthopedics & $1(0.2)$ & 47 (11.3) \\
\hline & Others & $20(4.0)^{1}$ & $31(7.4)^{2}$ \\
\hline
\end{tabular}

\begin{tabular}{llll} 
Drugs & & & \\
\hline DOACs user's type & Prevalent & $317(63.4)$ & $254(60.9)$ \\
& Incident & $148(29.6)$ & $138(33.1)$ \\
& Switch & $35(7.0)$ & $25(6.0)$
\end{tabular}

Legend:

Data are presented as a proportion, unless otherwise noted.

Other care units: gastroenterology, nephrology, geriatrics, hematology, ORL, urology, rheumatology, psychiatry and palliative care.

Other care units: geriatrics, gastroenterology, ORL, urology, hematology, neurosurgery, plastic surgery, endocrinology, gynecology, psychiatry, rheumatology and palliative care.

while it is no longer the case ${ }^{[23]}$.

In our study, no subjects with a mechanical heart valve were prescribed a DOAC. In fact, dabigatran was found to increase the risks of thromboembolic and bleeding events in such patients ${ }^{[24]}$.

No subjects received a concomitant medication that is contraindicated with DOACs. In a study conducted in Denmark, one patient $(0.02 \%)$ was taking ketoconazole or itraconazole at the beginning of treatment with dabigatran, and six patients $(0.1 \%)$ were prescribed itraconazole while on dabigatran ${ }^{[9]}$.

A low proportion of subjects (2.2\%) received a DOAC while having an estimated $\mathrm{CrCl}$ lower than $30 \mathrm{~mL} / \mathrm{min}$. Previous studies have also reported minimal use of dabigatran in patients with this level of renal function, with proportions varying between $0.4 \%$ and $2.9 \%$ [7. 10-13].

About 20\% of subjects were prescribed a DOAC with no recent values of liver enzymes available. This is of concern since DOACs are not recommended in the presence of severe hepatic impairment.

Our study is limited by several factors; a few numbers of patients on apixaban were included, several subjects were excluded because of incomplete discharge prescriptions (but their baseline characteristics were similar to the ones of included subjects), it was conducted in a single centre, and data were collected retrospectively. Also, the appropriateness criteria are based on limited evidence. Furthermore, factors influencing dose selection may not have been documented in the medical chart. DOACs are increasingly prescribed and physicians are now more familiar with their use, which could influence results from future studies on this subject.

\begin{tabular}{|c|c|c|c|}
\hline Table 4: & oriateness criteria for DOAC & prescriptions & \\
\hline \multicolumn{2}{|l|}{ Criteria } & \multirow{2}{*}{$\begin{array}{l}\text { Appropriate- } \\
\text { ness, n (\%) } \\
487 / 500 \\
(97.4)\end{array}$} & \multirow{2}{*}{$\begin{array}{l}95 \% \mathrm{Cl} \\
96.0-98.8\end{array}$} \\
\hline 1. Type of AF & Appropriate use & & \\
\hline 2. Mitral stenosis & Appropriate use & $\begin{array}{l}495 / 500 \\
(99.0)\end{array}$ & $98.1-99.9$ \\
\hline$\frac{3 . \text { CHADS2 score }}{\cdot \text { CHADS2 } \geq 1}$ & Appropriate use & $\begin{array}{l}473 / 473 \\
(100.0)\end{array}$ & \\
\hline - $\mathrm{CHADS2}=0$ & Appropriate use & $13 / 27(48.1)$ & \\
\hline & $\begin{array}{l}\text { Total number of appropri- } \\
\text { ate use }\end{array}$ & $\begin{array}{l}486 / 500 \\
(97.2)\end{array}$ & $95.8-98.7$ \\
\hline 4. Heart valves & Appropriate use & $\begin{array}{l}500 / 500 \\
(100.0)\end{array}$ & \\
\hline 5. Concomitant medication & Appropriate use & $\begin{array}{l}500 / 500 \\
(100.0)\end{array}$ & \\
\hline $\begin{array}{l}\text { 6. Renal function } \\
\text { - Dabigatran and rivar- } \\
\text { oxaban }\end{array}$ & $\begin{array}{l}\text { Appropriate use } \\
\text { Appropriate use }\end{array}$ & $\begin{array}{l}446 / 457 \\
(97.6) \\
43 / 43\end{array}$ & $96.5-99.0$ \\
\hline - Apixaban & $\begin{array}{l}\text { Total number of appropri- } \\
\text { ate use }\end{array}$ & $\begin{array}{l}(100.0) \\
489 / 500 \\
(97.8)\end{array}$ & \\
\hline 7. Liver enzymes levels & Appropriate use & $\begin{array}{l}395 / 407 \\
(97.1)\end{array}$ & $95.4-98.7$ \\
\hline $\begin{array}{l}\text { 8. a. Dose of dabigatran } \\
\text { - Dabigatran } 110 \mathrm{mg} \text { BID }\end{array}$ & Appropriate use & $\begin{array}{l}106 / 130 \\
(81.5)\end{array}$ & \\
\hline - Dabigatran $150 \mathrm{mg}$ BID & $\begin{array}{l}\text { Total number of appropri- } \\
\text { ate use }\end{array}$ & $\begin{array}{l}67 / 105 \\
(63.8) \\
173 / 235 \\
(73.6)\end{array}$ & $67.9-79.3$ \\
\hline $\begin{array}{l}\text { 8. b. Dose of rivaroxaban } \\
\text { - Rivaroxaban } 15 \mathrm{mg} \text { DIE } \\
\text { - Rivaroxaban } 20 \mathrm{mg} \text { DIE }\end{array}$ & $\begin{array}{l}\text { Appropriate use } \\
\text { Appropriate use } \\
\text { Total number of appropri- } \\
\text { ate use }\end{array}$ & $\begin{array}{l}31 / 61(50.8) \\
148 / 161 \\
(91.9) \\
179 / 222 \\
(80.6)\end{array}$ & $75.4-85.9$ \\
\hline $\begin{array}{l}\text { 8. c. Dose of apixaban } \\
\text { - Apixaban } 2,5 \mathrm{mg} \text { BID } \\
\text { - Apixaban } 5 \mathrm{mg} \text { BID }\end{array}$ & $\begin{array}{l}\text { Appropriate use } \\
\text { Appropriate use } \\
\text { Total number of appropri- } \\
\text { ate use }\end{array}$ & $\begin{array}{l}7 / 20(35.0) \\
23 / 23 \\
(100.0) \\
30 / 43(69.8)\end{array}$ & $55.5-84.1$ \\
\hline Overall appropriateness & Appropriate use & $\begin{array}{l}352 / 500 \\
(70.4)\end{array}$ & $66.4-74.4$ \\
\hline
\end{tabular}

Legend: C-Gault, Cockcroft-Gault; GFR, glomerular filtration rate; AST, aspartate aminotransferase; ALT, alanine aminotransferase; PO, per os; BID, twice a day; QD, once a day

\section{Conclusion}

Dabigatran, rivaroxaban and apixaban were commonly prescribed with a dose that was considered inappropriate. Our results support the need to implement measures to promote appropriate dosing of DAOCs. Further studies should investigate underdosing of DOACs in a larger setting.

Disclosures

This study was funded by Bayer,

Boehringer Ingelheim and

Bristol-Myers Squibb/

Pfizer alliance. 


\section{Acknowledgements}

We acknowledge the contribution of Martin Turgeon and the anticoagulotherapy committee of the Centre hospitalier universitaire de Sherbrooke for reviewing our appropriateness criteria.

\section{References}

1. Go A S, HylekE M, PhillipsK A, ChangY, HenaultL E, SelbyJ V, SingerD E. Prevalence of diagnosed atrial fibrillation in adults: national implications for rhythm management and stroke prevention: the AnTicoagulation and Risk Factors in Atrial Fibrillation (ATRIA) Study. JAMA. 2001;285 (18):2370-5.

2. Stewart S, HartC L, HoleD J, McMurrayJ J. Population prevalence, incidence, and predictors of atrial fibrillation in the Renfrew/Paisley study. Heart. 2001;86 (5):516-21.

3. Fondation des maladies du coeur. La fibrillation auriculaire - Attention au pouls 2014 [updated May 2014; cited 2015 April 22]. http://www.fmcoeur.qc.ca/site/c. kpIQKVOxFoG/b.5054321/k.759F/Maladies_du_coeur__La_fibrillation_ auriculaire.htm. 2014;0:0-0.

4. AJ Camm, PKirchhof, GYLip, ISchotten, SErnst, alet. Guidelines for the management of atrial fibrillation: the Task Force for the Management of Atrial Fibrillation of the European Society of Cardiology (ESC). Eur. Heart J. 2010;0:2369-429.

5. Institut national d'excellence en santé et services sociaux . Médicament anticoagulothérapie chez l'adulte / Fibrillation auriculaire 2012 [updated March 2014; cited 2015 September 15]. https://www.inesss.qc.ca/fileadmin/doc/ INESSS/Rapports/Medicaments/INESSS_outil_choix_anticoagulotherapie.pdf. 2012;0:0-0.

6. F Boehlen, PMoerloose. New anticoagulants: better knowledge, better prescriptions. Rev Med Suisse. 2012;0:96-9.

7. Armbruster Anastasia L, BuehlerKatie S, MinSun H, RileyMargaret, DalyMichael W. Evaluation of dabigatran for appropriateness of use and bleeding events in a community hospital setting. Am Health Drug Benefits. 2014;7 (7):376-84.

8. Carley Blake, GriesbachSara, LarsonTonja, KruegerKori. Assessment of dabigatran utilization and prescribing patterns for atrial fibrillation in a physician group practice setting. Am. J. Cardiol. 2014;113 (4):650-4.

9. TB Larsen Rosenzweig M, et al., RasmussenLH, SkjothF, KMDue, TCallreus, MRosenzweig. Efficacy and safety of dabigatran etexilate and warfarin in "realworld" patients with atrial fibrillation:a prospective nationwide cohort study. J Am Coll Cardiol. 2013;0:2264-73.

10. Michel Jonathan, MundellDavid, BogaTau, SasseAlexander. Dabigatran for anticoagulation in atrial fibrillation - early clinical experience in a hospital population and comparison to trial data. Heart Lung Circ. 2013;22 (1):50-5.

11. Sidman Eric, ProbstLuke A, DarkoWilliam, MillerChristopher D. Evaluation of dabigatran utilization and risk among hospitalized patients. Ann Pharmacother. 2014;48 (3):349-53.

12. AS Larock, FMullier, ALSennesael, JDouxfils, BDevalet, cChatelain, alet. Appropriateness of prescribing dabigatran etexilate and rivaroxaban in patients with nonvalvular atrial fibrillation: a prospective study. Ann Pharmacother. 2014;0:1258-68.

13. Tellor K B, PatelS, ArmbrusterA L, DalyM W. Evaluation of the appropriateness of dosing, indication and safety of rivaroxaban in a community hospital. J Clin Pharm Ther. 2015;40 (4):447-51.

14. Sorensen, GGislason, CTorp-Pedersen, JBOlesen, ELFosbol, MWHvidtfeldt, alet. Dabigatran use in Danish atrial fibrillation patients in 2011: a nationwide study. BMJ Open. 2013;0:1750-64.

15. SJ Connolly, MDEzekowitz, SYusuf,JEikelboom, AParekh,JOldgren. Dabigatran versus warfarin in patients with atrial fibrillation. N Engl J Med. 2009;0:1139-51.

16. MR Patel, KWMahaffey, JGarg, GPan, DESinger, WHacke, alet. Rivaroxaban versus warfarin in nonvalvular atrial fibrillation. N Engl J Med. 2011;0:883-91.

17. Granger, JHAlexander, JJMcMurray, RDLopes, EMHylek, MHanna, alet.
Apixaban versus warfarin in patients with atrial fibrillation. N Engl J Med. 2011;0:981-91.

18. Skanes Allan C, HealeyJeff S, CairnsJohn A, DorianPaul, GillisAnne M, McMurtryM Sean, MitchellL Brent, VermaAtul, NattelStanley. Focused 2012 update of the Canadian Cardiovascular Society atrial fibrillation guidelines: recommendations for stroke prevention and rate/rhythm control. Can J Cardiol. 2012;28 (2):125-36.

19. Canada Santé. Pradaxa/Pradax (dabigatran etexilate) - Nouvelle contre-indication chez les patients porteurs d'une valvule cardiaque artificielle et nécessitant une anticoagulothérapie en raison deleur valvulopathie - Avis aux hôpitaux (RA-16389) 2012 [updated March 1 2013; cited 2013 January 7]. http://canadiensensante. gc.ca/recall-alert-rappel-avis/hc-sc/2012/16389a-fra.php. 2012;0:0-0.

20. BMS. Eliquis (apixaban) package insert Kirkland and Montréal, QC2015. Europace. 0;0:0-0.

21. Ltée Boehringer Ingelheim. Pradaxa (dabigatran etexilate) package insert Burlington, ON2015 . . 0;0:0-0

22. Bayer Inc. Xarelto (rivaroxaban) package insert Mississauga. ON2015. 2015;0:0-0. 23. A Verma, JACairns, LBMitchell, LMacle, IGStiell, DGladstone, atet. 2014 focused update of the Canadian Cardiovascular Society Guidelines for the management of atrial fibrillation. Mayo Clin. Proc. 2014;0:1114-30.

24. Eikelboom John W, ConnollyStuart J, BrueckmannMartina, GrangerChristopher B, KappeteinArie P, MackMichael J, BlatchfordJon, DevennyKevin, FriedmanJeffrey, GuiverKelly, HarperRuth, KhderYasser, LobmeyerMaximilian T, MaasHugo, VoigtJens-Uwe, SimoonsMaarten L, Van de WerfFrans. Dabigatran versus warfarin in patients with mechanical heart valves. N. Engl. J. Med. 2013;369 (13):1206-14 